\title{
The Effect of a High Fibre Diet on Diabetic Nephropathy in the db/db Mouse
}

\author{
S.M.Lee \\ Health Sciences Center, University of Arizona, Tucson, Arizona, USA
}

Summary. Genetically diabetic mice (C57 BLKsJ db/ db) aged 5-6 weeks were given a diet containing $20 \%$ by weight of non-nutritive bulk and compared with age matched control diabetic mice on a normal diet (fibre content $4.5 \%$ ) and non-diabetic mice. The duration of study was 12 weeks. No adverse effects were observed in animals given the high fibre diet. Total food consumption was greater in mice receiving the fibre enriched diet, but their absolute caloric intake was $6 \%$ less than control diabetic mice. Both groups exhibited similar rates of growth and development. Water intake in the experimental diabetic mice was reduced and similar to that of normal non-diabetic mice. Fasting blood glucose was significantly decreased in the experimental diabetic mice at 12 weeks. Renal pathological lesions in the control diabetic mice showed glomerular mesangial expansion and deposition of immunoglobulins within the mesangium. The experimental diabetic animals exhibited significantly less renal pathology, including light and immunofluorescent lesions. It is concluded that addition of non-absorbable fibre to the diet of genetically diabetic mice improves glycaemic control and retards the development of diabetic nephropathy.

Key words: Diabetes, $\mathrm{db} / \mathrm{db}$ mouse, high fibre diet, diabetic nephropathy.

Diabetes in the C57BLKs.J db/db mouse is characterized by hyperphagia, progressive obesity and widespread pathological abnormalities [1]. Hyperinsulinaemia and down-regulation of insulin receptors precludes the use of exogenous insulin as a successful method to control the blood glucose [2]. As an experimental model, this mouse resembles Type 2 (non-insulin-dependent) diabetes in man. In a previous study we showed that controlled dietary intake, sufficient to prevent obesity, was associated with normal blood glucose levels and prevented the development of pathological lesions in the kidney [3].

Recently, much interest has focussed on the role of dietary fibre content as a factor in the development and severity of the diabetic state. Studies involving diabetic patients have demonstrated improved glucose tolerance, decreased post-prandial hyperglycaemia and diminished insulin secretory rates following a test meal containing non-absorbable fibre.

This study was designed to evaluate the effects of an increased dietary fibre content in the $\mathrm{db} / \mathrm{db}$ mouse, with specific reference to blood glucose control and the development of diabetic nephropathy.

\section{Materials and Methods}

\section{Animals}

$\mathrm{C} 57 \mathrm{BlKsJ} \mathrm{db} / \mathrm{db}$ mice were obtained from a breeding colony maintained at the University of Arizona Medical Center. Animals heterozygous for the diabetic gene $(\mathrm{db} /+)$ were bred and the diabetic offspring were recognized at the age of 5 weeks, by the appearance of early obesity. Animals were entered into the study at the time when this obesity was clearly apparent. Mice were housed at $22^{\circ} \mathrm{C}$, and exposed to $12 \mathrm{~h}$ of daylight.

\section{Diet Preparation}

Control animals in this study received normal mouse chow (Wayne Lab-Blox, Chicago, Illinois, USA), which contains $4.5 \%$ crude fibre, $24 \%$ protein and $4.0 \%$ fat. The experimental diet was prepared from normal chow as follows:- the food pellets were crushed to the consistency of a fine powder and Alphacel was added to produce a final concentration of $20 \%$ by weight. Alphacel, a non-nutritive bulk agent, contains $1-4$ glucan $90 \%$, pentosan $7 \%$ and lignin $0.3 \%$. This powdered chow as reconstituted to the usual pellet form. Preparation of this diet was undertaken by ICN Nutritional Biochemicals, Cleveland, Ohio, USA. 
Table 1. Fasting plasma glucose levels in control diabetic mice (normal diet), experimental diabetic mice (high fibre diet) and nondiabetic mice (high fibre diet) during the 12 week study period

\begin{tabular}{llll}
\hline & \multicolumn{3}{l}{$\begin{array}{l}\text { Fasting plasma glucose levels } \\
(\mathrm{mmol} / \mathrm{l})\end{array}$} \\
\cline { 2 - 4 } & Week 4 & Week 8 & Week 12 \\
\hline $\begin{array}{l}\text { Control diabetic mice }(n=11) \\
\begin{array}{l}\text { Experimental diabetic } \\
\text { mice }(n=6)\end{array}\end{array}$ & $8.9 \pm 1.0$ & $12.8 \pm 1.9$ & $18.3 \pm 2.9$ \\
Non-diabetic mice $(n=6)$ & $3.9 \pm 0.33$ & $4.1 \pm 1.7$ & $4.4 \pm 0.33$ \\
\hline
\end{tabular}

Blood samples obtained following a $12 \mathrm{~h}$ fast

Results expressed as mean \pm SEM

${ }^{\text {a }} p<0.05$ compared with control diabetic mice

Table 2. Organ weights of mice at time of sacrifice

\begin{tabular}{llll}
\hline & \multicolumn{2}{l}{ Organ weights $(\mathrm{mg})$} \\
\cline { 2 - 4 } & Heart & Liver & Kidneys \\
\hline Control diabetic mice & $131 \pm 6$ & $2635 \pm 213$ & $365 \pm 15$ \\
Experimental diabetic mice & $147 \pm 9$ & $2724 \pm 208$ & $388 \pm 19$ \\
Non-diabetic mice & $119 \pm 9^{\mathrm{b}}$ & $968 \pm 28^{\mathrm{a}}$ & $274 \pm 18^{\mathrm{a}}$ \\
\hline
\end{tabular}

Results expressed as mean \pm SEM

a $p<0.01$ compared with control diabetic mice. ${ }^{b} p<0.05$ compared with experimental diabetic mice

\section{Experimental Protocol}

Three groups of animals were designated. Group $1(n=6)$ : heterozygote non-diabetic animals $(+/ \mathrm{db})$ received the fibre enriched diet. Group $2(n=6)$ : experimental diabetic mice $(\mathrm{db} / \mathrm{db})$ received the fibre enriched diet. Group $3(n=11)$ : control diabetic mice $(\mathrm{db} /$ $\mathrm{db}$ ) received normal chow. In a preliminary experiment, it was shown that the fibre enriched diet administered to non-diabetic mice had no effect on their growth, blood glucose or renal histology. Animals were entered into the study at the age of 5-6 weeks, a time when early obesity was clearly evident. They were permitted access to food and water ad libitum throughout the study which lasted for 12 weeks.

Animals were weighed three times per week at $0900 \mathrm{~h}$. Food and water consumption were measured on a weekly basis. Plasma glucose was measured following overnight food deprivation (12 h) on weeks 4,8 and 12 . The blood samples were obtained from the retroorbital venous plexus without anaesthesia and glucose was measured on a Beckman glucose analyzer. At the conclusion of the study following sacrifice, the heart, liver and kidneys were weighed and the kidneys examined by light and immunofluorescence microscopy.

\section{Histological Methods}

Kidney tissue for immunofluorescence was snap-frozen in isopentane pre-cooled in liquid nitrogen, and sectioned at 5-6 $\mu$ on a cryomicrotome. Sections were stained for the presence of endogenous immunoglobulins (IgG, $\operatorname{IgM}, \operatorname{IgA}$ ) and albumin. Fluoresceinlabelled antisera were purchased from Cappel Laboratories, Cochranville, $\mathrm{Pa}$, USA, and their purity and specificity determined by methods described previously [4]. Tissues were examined on a Nikon microscope using epifluorescent optics.
The intensity and distribution of glomerular fluorescent staining was graded as follows: trace-fluorescence just above background, and $1+$ through $4+$ representing increasing degrees of staining. Sections were photographed using Kodak Tri-X film, with equal exposure time and processing. Statistical comparison between samples was undertaken using the Mann-Whitney test for non-parametric data [5].

For light microscopy, tissue was fixed in $10 \%$ buffered formalin, embedded in paraffin and sectioned at $5 \mu$. Sections were stained with haematoxylin/eosin and periodic acid Schiff reagent. The early changes of diabetic nephropathy in the $\mathrm{db} / \mathrm{db}$ mouse include glomerular mesangial widening which is most apparent in sections stained with periodic acid Schiff. To evaluate the effects of the experimental diet, these changes in glomerular mesangial thickening were graded in a semi-quantitative manner from 0 through $4+$. Mean \pm SEM were calculated for each group and Student's t-test was used to determine differences between groups.

The processes of formalin fixation, paraffin embedding and variable section thickness precludes absolute quantitative measurements of glomerular size or comparisons with other reported values for these parameters. The described methodology permits a valid comparison between groups in which the tissues have been processed in an identical fashion.

All histological sections, including light and immunofluorescence samples, were read without knowledge of the identity of the tissue.

\section{Results}

The fibre enriched diet caused no changes in the behaviour or gross appearance of the mice. In both diabetic and non-diabetic mice receiving the special diet, the stool was markedly increased in bulk and lighter in colour, compared with the mice on normal chow.

Diabetic mice receiving the fibre enriched diet consumed $515 \mathrm{~g}$ during the 12 weeks of study compared with $466 \mathrm{~g}$ by diabetic mice receiving normal chow. However their total caloric intake was $6 \%$ lower because of the $20 \%$ fibre content in the experimental diet. The growth rate and final weight achieved by both groups of diabetic mice were similar.

Water intake was altered significantly by the fibre enriched diet. Control diabetic mice exhibited a progressive increase in water consumption throughout the study, consistent with their hyperglycaemia and glycosuria. By week 12, each animal was drinking over $100 \mathrm{ml} /$ week. In contrast, the experimental diabetics consumed approximately $40 \mathrm{ml} /$ week, suggesting attenuation of their glycosuria. The difference between the two groups was discernible by week 3 of the study. Non-diabetic mice drank approximately $30 \mathrm{ml} /$ week.

At week 4 of the study, fasting plasma glucose levels were similar in control $(7.9 \pm 1.0 \mathrm{mmol} / 1)$ and experimental diabetic $(8.7 \pm 1.8 \mathrm{mmol} / \mathrm{l})$ groups (Table 1) At later time periods (weeks 8 and 12), the control diabetic mice exhibited progressive hyperglycaemia, whereas fasting glucose in the experimental diabetic mice remained stable. The two diabetic groups differed significantly at week 12 . Glucose 

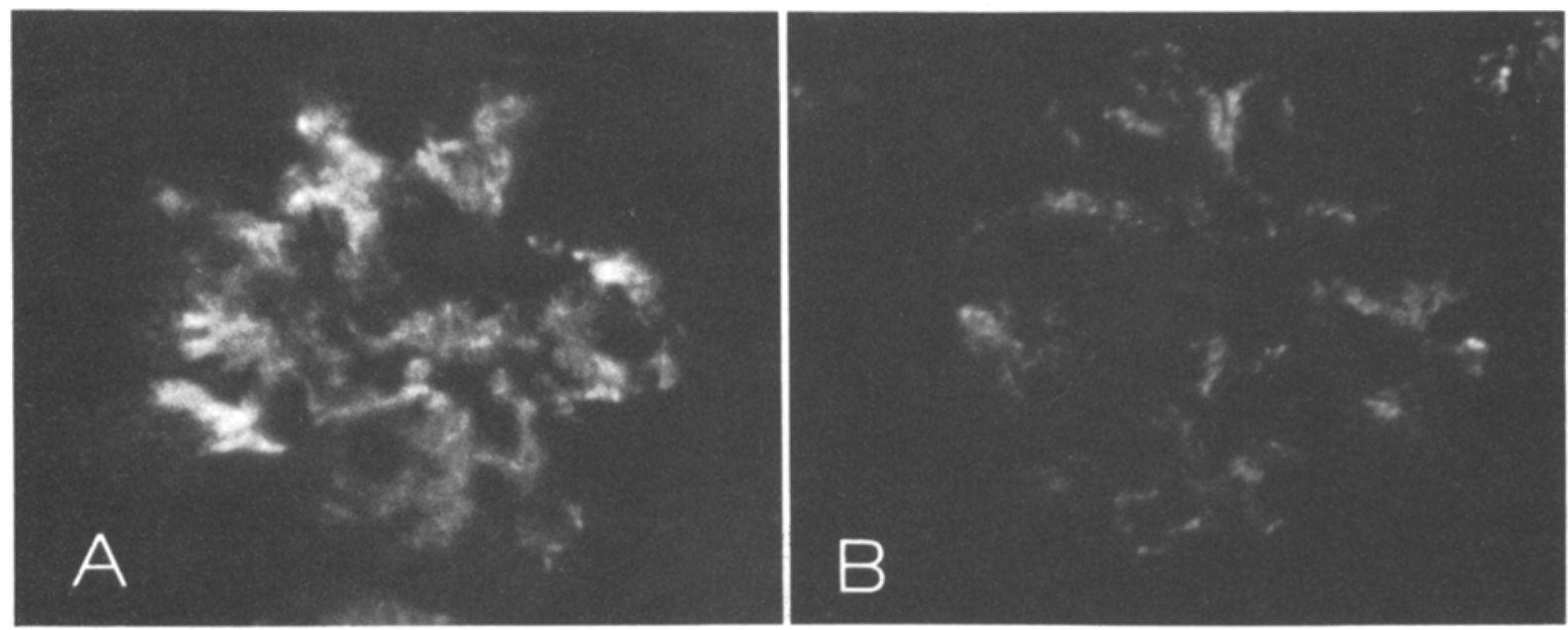

Fig. 1. Representative immunofluorescent micrographs stained for endogenous IgM. (A) Control diabetic mouse; (B) Experimental diabetic mouse. The control diabetic mouse shows diffuse mesangial immunoglobulin deposition with $3+$ intensity, whereas the experimental diabetic mouse shows $1+$ staining $(\times 200)$

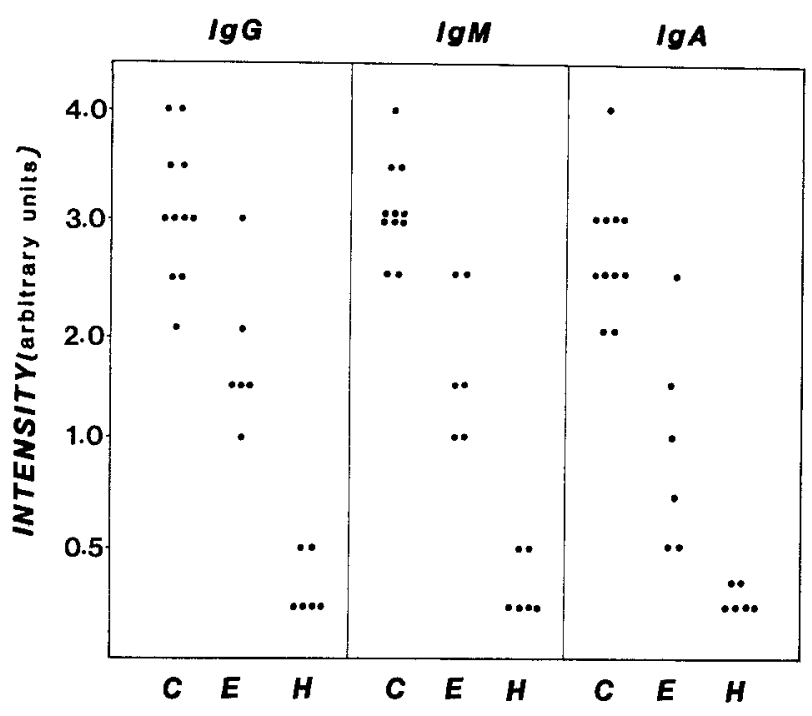

Fig. 2. Schematic representation of glomerular mesangial immunofluorescent staining. C: control diabetic mice; E: experimental diabetic mice; $\mathrm{H}$ : heterozygote non-diabetic mice. Control and experimental diabetic groups differ significantly with each immunoglobulin $(\operatorname{IgG} p<0.01, \operatorname{IgM} p<0.001, \operatorname{Ig} \mathrm{A} p=0.001)$

levels in the non-diabetic heterozygote mice were less than the experimental diabetic group at each time period.

The weights of liver, heart and kidneys were similar in the control and experimental diabetic animals (Table 2) and the gross appearance of the viscera were indistinguishable in these two groups.

\section{Immunofluorescence}

Immunopathological examination of the kidneys from control diabetic mice showed diffuse immuno- globulin deposition in the glomeruli with a staining intensity of $3+$. The distribution was mainly confined to the glomerular mesangium with extension to the juxta-glomerular region where large accumulations of immunoglobulin were frequently observed (Fig. 1). The experimental diabetic animals exhibited significantly less staining with each immunoglobulin, the intensity being $1+$ to $-2+$. The non-diabetic heterozygote mice showed 0 trace immunoglobulin deposition. These results are depicted schematically in Figure 2.

\section{Light Microscopy}

The control diabetic mice showed diffuse widening and thickening of the glomerular mesangium, these changes being due to increased mesangial matrix material (Fig.3). Glomerular cellularity and capillary wall thickness were both within normal limits. The tubules exhibited widespread vacuolization and the interstitial structures and blood vessels were normal. The experimental diabetic animals displayed substantially less mesangial expansion and were clearly distinguishable from the control diabetic mice. However, the appearance of the glomeruli in the experimental diabetic mice was different from the non-diabetic animals, whose mesangium appeared as a fine lacy network by periodic acid Schiff stain. The relative degree of glomerular thickening for the three groups of mice is described in Table 3 .

\section{Discussion}

The widespread ingestion of fibre deficient diets has been postulated as a causative factor in the increased 

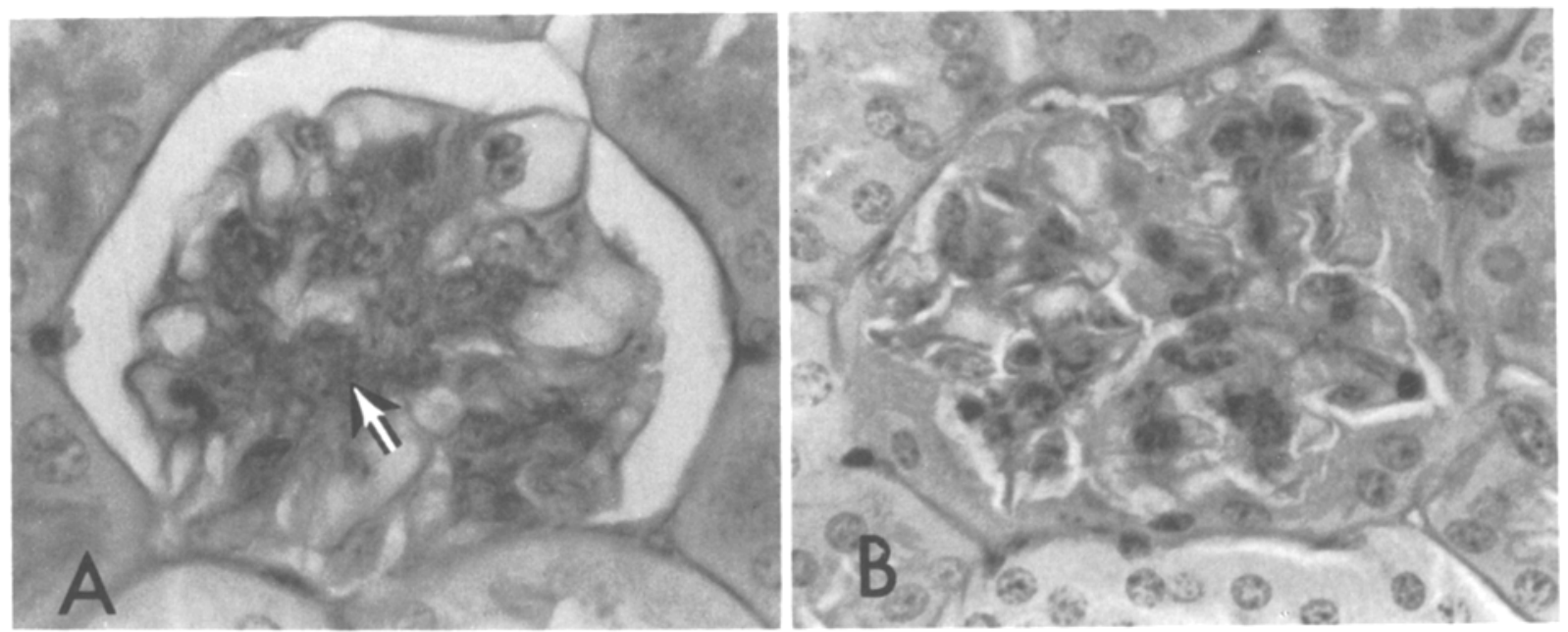

Fig. 3. Representative light micrographs from a control diabetic mouse (A) and an experimental diabetic mouse (B). The control mouse shows well defined mesangial matrix expansion (arrow), which is not present in the experimental diabetic mouse (periodic acid Schiff $\times 200$ )

Table 3. Index of glomerular mesangial thickening in control diabetic mice (normal diet), experimental diabetic mice (high fibre diet) and non-diabetic mice (high fibre diet)

\begin{tabular}{ll}
\hline Control diabetic mice $(n=11)$ & $2.9 \pm 0.1$ \\
Experimental diabetic mice $(n=6)$ & $2.0 \pm 0.2^{\mathrm{a}}$ \\
Non-diabetic mice $(n=6)$ & $1.5 \pm 0.1$ \\
\hline
\end{tabular}

Tissues prepared for light microscopy and stained with periodic acid Schiff. Results are expressed as mean \pm SEM.

${ }^{a}$ Experimental diabetic mice differ from controls $(p<0.01)$

incidence of Type 2 diabetes in the developed nations. The use of a fibre enriched diet has been suggested as an additional therapy in the management of patients with diabetes. In this study, it has been shown that the addition of non-nutritive bulk to the diet of the genetically diabetic mouse caused a significant improvement in metabolic control and decreased diabetic renal pathology.

Several studies in man with diabetes mellitus have demonstrated the beneficial effects of dietary fibre on metabolic control. The addition of guar gum or pectin to a test meal was associated with decreased postprandial hyperglycaemia and insulin secretion in patients with Type 2 diabetes [6]. Ingestion of fibre enriched diet over a period of 14 days was associated with decreased levels of insulin, glucose and gastric inhibitory polypeptide [7]. In patients with Type 1 (insulin-dependent) diabetes, addition of fibre to the diet permitted a reduction in exogenous insulin requirements [8].

The genetically diabetic mouse utilized in the present study resembles Type 2 adult onset diabetes in man. During the first 4 months of life these animals are hyperphagic and develop progressive obesity. The initial metabolic abnormality is hyperinsulinaemia at
10 days of age, which persists until $4-5$ months when insulin levels decline in association with degenerative changes in the pancreatic islets [9]. Hyperinsulinaemia and down regulation of insulin receptors is associated with resistance to the effects of exogenous insulin. These mice exhibit defective thermoregulation [10] and possess an enhanced metabolic efficiency with the result that modest restriction of food intake does not impair their usual growth [11]. In a previous study, we showed that dietary restriction sufficient to prevent the development of obesity resulted in normal blood glucose levels and prevented the nephropathy in these mice [3]. This is in accordance with observations in other models of experimental diabetes which have shown that metabolic control prevents the pathological changes in the kidney $[12,13]$.

In this study, the mice of the high fibre diet consumed $515 \mathrm{~g}$ of food, while the control animals ate $466 \mathrm{~g}$ during the 12 weeks of study. However the total caloric intake was $6 \%$ lower in the experimental group. It is unlikely that this degree of caloric restriction was responsible for the observed changes in diabetic control as their growth rate was unimpaired. Our own observations and those of other workers have indicated that greater dietary restriction is necessary to lower the blood glucose.

The mechanism by which fibre ingestion improves glycaemic control in diabetic animals is not completely understood. It has been shown that a fibre deficient test meal is consumed more rapidly, causes less satiety, and produces a higher post-prandial insulin peak [14]. However, other factors are probably of more importance, including the effects on gastric emptying and intestinal motility, both of which are decreased following fibre ingestion [15]. In addition, the physical nature of the fibre, specifically its viscosi- 
ty, influences these parameters [16]. Guar, tragacanth and pectin all decrease intestinal transit time, whereas methylcellulose and bran have the opposite effect [15]. It has been suggested that the non-absorbed fibre exists as a gel within the intestine which increases the unstirred layer adjacent to the villi, thereby decreasing the rate of nutrient absorption.

The nephropathy which develops in the $\mathrm{db} / \mathrm{db}$ mouse is characterized in its early stages by the appearance of immunoglobulin deposition in the glomerular mesangium [4]. This abnormality is present at the age of 2 months and is followed by mesangial matrix expansion which can be recognized by 3 months. These changes are similar to those observed in other models of experimental diabetes. It has been demonstrated in diabetic rats and in the $\mathrm{db} / \mathrm{db}$ mouse that the pathological changes in the kidney are dependent on and responsive to control of the diabetic state, i.e. blood glucose $[3,12.13]$. The factors which determine the development of mesangial matrix expansion are not understood. The deposition of immunoglobulin and other proteins in the glomerular mesangium is not an immunological phenomenon as there is no evidence of inflammation, necrosis or white blood cell infiltration. It is probable that the glomerular lesion in diabetes results from an alteration in mesangial metabolism and changes in renal haemodynamics.

Increased glomerular filtration is a characteristic occurrence in the early stages of human and experimental diabetes, and has been demonstrated in the $\mathrm{db} / \mathrm{db}$ mouse [17]. Recent observations have indicated that mesangial increase may occur as a consequence of glomerular hyperfiltration which follows partial nephrectomy in the rat [18]. The influence of renal haemodynamic factors in the pathogenesis of diabetic nephropathy is not understood and it is not known whether this parameter was influenced by the dietary treatment in this experimental protocol.

It has been shown that the mesangial matrix expansion which occurs in diabetic rats is in part reversible following control of the diabetic state with islet cell transplantation or transplantation of the abnormal kidney into a non-diabetic host [14]. The changes in the glomerular mesangial matrix appear to be sensitive to the diabetic internal milieu. In the present study, fasting blood glucose was lowered but not to normal levels by the administration of a fibre-enriched diet. Amelioration of the pathological changes in the kidney in these animals is consistent with the degree of metabolic control achieved by the experimental diet. This study suggests that dietary fibre content may be important in the management of patients with Type 2 diabetes.

Acknowledgements. This work was supported in part by grants from the Arizona Kidney Foundation and the American Heart Association - Arizona Affiliate. E. Hurd and K. Massey provided excellent technical assistance, and I thank F. Campion and C.Ayala for secretarial help.

\section{References}

1. Coleman DL, Hummel KP (1966) Studies with the mutation, diabetes, in the mouse. Diabetologia 3: 238-248

2. Sol AH, Kohn CR, Neville DM, Roth J (1975) Insulin receptor deficiency in genetic and acquired obesity. J Clin Invest 56: $769-780$

3. Lee SM, Bressler R (1981) Prevention of diabetic nephropathy by diet control in the $\mathrm{db} / \mathrm{db}$ mouse. Diabetes $30: 106-111$

4. Lee SM, Graham A (1980) Early immunopathologic events in experimental diabetic nephropathy: A study in $\mathrm{db} / \mathrm{db}$ mice. Exp Mol Path 33: 323-332

5. Siegel S (1956) Non-parametric statistics for the behavioral sciences. McGraw-Hill, New York, pp 95-156

6. Jenkins DJA, Goff DV, Leeds AR, Alberti KGMM, Woliver TMS, Gassull MA, Hockaday TDR (1976) Unabsorbable carbohydrates and diabetes: decreased post-prandial hyperglycaemia. Lancet 2: 172-174

7. Kay RM, Grobin W, Track NS (1981) Diets rich in natural fibre improve carbohydrate tolerance in maturity-onset- non-insulin dependent diabetics. Diabetologia 20: 18-21

8. Kiehm G, Anderson JW, Ward K (1976) Beneficial effects of a high carbohydrate, high fiber diet on hyperglycemic diabetic men. Am J Clin Nutr 29:895-899

9. Baetens D, Stefan Y, Ravazzola M, Malaisse-Sagal F, Coleman DL, Orci L (1978) Alterations of islet cell populations in spontaneously diabetic mice. Diabetes 27:1-7

10. Trayburn $P(1979)$ Thermoregulation in the diabetic-obese (db/ db) mouse. Pfluegers Arch 380:227-232

11. Wyse BM, Dulin WE (1970) The influence of age and dietary conditions on diabetes in the $\mathrm{db} / \mathrm{db}$ mouse. Diabetologia 6 : 268-273

12. Rasch R (1979) Prevention of diabetic glomerulopathy in streptozotocin diabetic rats by insulin treatment. Diabetologia 17 : 243-248

13. Mauer SM, Steffes MW, Sutherland DER, Najarian JS, Michael AF, Brown DM (1974) Studies of the rate of regression of the glomerular lesions in diabetic rats treated with pancreatic islet transplantation. Diabetes 24: 280-285

14. Haber GB, Heaton KW, Murphy D (1977) Depletion and disruption of dietary fibre. Effects on satiety, plasma glucose and serum insulin. Lancet 2: 679-682

15. Caspary WF, Eisenhaus B, Sufke U, Ptok M, Blume R, Lambcke B, Creutzfeldt W (1980) Effect of dietary fiber on absorption and motility. Front Horm Res 7: 202-217

16. Jenkins DJA, Wolever TMS, Leeds AR, Gassull MA, Haisman P, Dilwari J, Goff DV, Metz GL, Alberti KGMM (1978) Dietary fibres, fibre analogues, and glucose tolerance: Importance of viscosity. Br Med J 1: 1392-1394

17. Gartner K (1978) Glomerular hyperfiltration during the onset of diabetes mellitus in two strains of diabetic mice. Diabetologia $15: 59-63$

18. Hostetter TH, Olson JL, Rennke HG, Venkatachalam MA, Brenner BM (1981) Hyperfiltration in remnant nephrons: A potentially adverse response to renal ablation. Am J Physiol 241: $85-94$

Received: 1 June 1981

and in revised form: 20 November 1981

Stanley M. Lee, MB, FRCP(C)

Department of Medicine

Health Sciences Center

University of Arizona

Tucson, Arizona 85724, USA 